\title{
Energetic Characteristics of the New Transthyretin Variant A25T May Explain Its Atypical Central Nervous System Pathology
}

\author{
Yoshiki Sekijima, Per Hammarström, Miyuki Matsumura, Yuko Shimizu, \\ Makoto Iwata, Takahiko Tokuda, Shu-ichi Ikeda, and Jeffery W. Kelly \\ Department of Chemistry and The Skaggs Institute of Chemical Biology (YSe, PH, JWK), The Scripps Research \\ Institute, La Jolla, California; and Third Department of Medicine (YSe, TT, SI), Shinshu University School of \\ Medicine, Matsumoto, and Department of Neurology (MM, YSh, MI), Neurological Institute, Tokyo Women's \\ Medical University School of Medicine, Tokyo, Japan
}

\begin{abstract}
SUMMARY: Transthyretin (TTR) is a tetrameric protein that must misfold to form amyloid fibrils. Misfolding includes rate-limiting tetramer dissociation, followed by fast tertiary structural changes that enable aggregation. Amyloidogenesis of wild-type (WT) TTR causes a late-onset cardiac disease called senile systemic amyloidosis. The aggregation of one of $>80$ TTR variants leads to familial amyloidosis encompassing a collection of disorders characterized by peripheral neuropathy and/or cardiomyopathy. Prominent central nervous system (CNS) impairment is rare in TTR amyloidosis. Herein, we identify a new A25T TTR variant in a Japanese patient who presented with CNS amyloidosis at age 42 and peripheral neuropathy at age 44. The A25T variant is the most destabilized and fastest dissociating TTR tetramer published to date, yet, surprising, disease onset is in the fifth decade. Quantification of A25T TTR in the serum of this heterozygote reveals low levels relative to WT, suggesting that protein concentration influences disease phenotype. Another recently characterized TTR CNS variant (D18G TTR) exhibits strictly analogous characteristics, suggesting that instability coupled with low serum concentrations is the signature of CNS pathology and protects against early-onset systemic amyloidosis. The low A25T serum concentration may be explained either by impaired secretion from the liver or by increased clearance, both scenarios consistent with A25T's low kinetic and thermodynamic stability. Liver transplantation is the only known treatment for familial amyloid polyneuropathy. This is a form of gene therapy that removes the variant protein from serum preventing systemic amyloidosis. Unfortunately, the choroid plexus would have to be resected to remove A25T from the CSF-the source of the CNS TTR amyloid. Herein we demonstrate that small-molecule tetramer stabilizers represent an attractive therapeutic strategy to inhibit A25T misfolding and CNS amyloidosis. Specifically, 2-[(3,5dichlorophenyl)amino]benzoic acid is an excellent inhibitor of A25T TTR amyloidosis in vitro. (Lab Invest 2003, 83:409-417).
\end{abstract}

$T$ ransthyretin (TTR) is a $55-\mathrm{kd}$ homotetrameric protein composed of 127 -residue $\beta$-sheet-rich subunits that is present in serum (3.6 to $7.2 \mu \mathrm{M})$ and cerebral spinal fluid (CSF; 0.04 to $0.4 \mu \mathrm{m}$ ). The function of TTR is to transport L-thyroxine $\left(\mathrm{T}_{4}\right)$ and holo-retinolbinding protein. TTR is one of $>20$ nonhomologous amyloidogenic proteins that can be transformed into fibrils and other aggregates that lead to pathology in humans. These diseases do not seem to be caused by loss of function as a result of protein aggregation; instead, aggregation seems to cause neuronal/cellular dysfunction by a mechanism that is not yet clear.

\footnotetext{
DOI: 10.1097/01.LAB.0000059937.11023.1F

Received November 13, 2002.

This study was supported by the National Institutes of Health (DK 46335), the Skaggs Institute of Chemical Biology, The Lita Annenberg Hazen Foundation, and a fellowship to Y. Sekijima from the Japan Health Science Foundation.

Address reprint requests to: Dr. Jeffery W. Kelly, Department of Chemistry and The Skaggs Institute of Chemical Biology, The Scripps Research Institute, 10550 N. Torrey Pines Road, BCC 265, La Jolla, California 92037.E-mail: jwk@scripps.edu
}

Rate-limiting tetramer dissociation and tertiary structural changes within the monomer enables aggregation of wild-type (WT) TTR, leading to cardiac amyloidosis in elderly people (senile systemic amyloidosis). More than 80 mutations are known to accelerate TTR amyloidosis, exacerbating pathology by thermodynamic and/or kinetic destabilization (Connors et al, 2000; Hammarström et al, 2002; Ikeda et al, 2002; McCutchen et al, 1995). These TTR variants lead to diseases collectively referred to as familial amyloid polyneuropathy (FAP), in which aggregation putatively causes peripheral and autonomic nervous system dysfunction. Familial mutations can also lead to cardiac dysfunction, particularly in black individuals with the V122I TTR mutation (familial amyloid cardiomyopathy). Involvement of other organs such as the kidney, intestine, and eye is ordinary, but prominent central nervous system (CNS) impairment is rare in TTR amyloidosis. TTR amyloid deposition on the leptomeninges and subarachnoid vessels seems to cause CNS symptoms such as recurrent subarachnoid hemorrhage, hearing loss, ataxia, dementia, seizures, myelopathy, brain hemorrhage, and brain infarction. A 
few TTR variants are associated with CNS amyloidosis (Brett et al, 1999; Ellie et al, 2001; Garzuly et al, 1996; Ikeda et al, 2002; Mascalchi et al, 1999; Petersen et al, 1997; Uemichi et al, 1997; Uemichi et al, 1999); however, the requirements for a CNS selective disease as opposed to a systemic amyloid disease are unclear, and this study represents our first attempt to gain some insight.

Recently, we diagnosed an patient who had FAP and a novel TTR mutation, threonine 25 replacing alanine (A25T). He presented with CNS amyloidosis at age 42 and peripheral nerve impairment at age 44 and exhibited very low levels of A25T TTR in the serum. Herein, we evaluate the biophysical characteristics of the A25T CNS variant revealing that the A25T TTR tetramer exhibits very low thermodynamic and kinetic stability. We show that the low serum concentration of A25T inhibits its amyloidosis, presumably explaining why this mutation does not result in an early-onset peripheral disease. We speculate that the high L-thyroxine $\left(T_{4}\right)$ concentration in the choroid plexus may be able to chaperone more A25T into the CSF than is desirable, which is problematic because the concentration of $T_{4}$ in the CSF is insufficient to keep A25T TTR tetrameric, which would lead to misfolding in the leptomeninges proximal to the site of secretion, as observed. Studies within demonstrate that $T_{4}$ can stabilize the tetramer and prevent misfolding but not nearly as well as a small molecule designed for this function-providing indirect support for the $\mathrm{T}_{4}$ chaperoning hypothesis. Importantly, we demonstrate that tetramer stabilizers represent an attractive therapeutic strategy to inhibit A25T postsecretory misfolding and CNS amyloidosis. Specifically, 2-[(3,5-dichlorophenyl)amino]benzoic acid is an excellent inhibitor of A25T TTR amyloidosis in vitro.

\section{Results}

\section{Evaluating the pH Dependence and Rate of A25T TTR Fibril Formation Relative to WT TTR}

TTR is converted into amyloid by rate-limiting $\mathrm{pH}-$ mediated tetramer dissociation followed by tertiary structural changes that enable self-assembly of the monomeric amyloidogenic intermediate. Unlike WT TTR, which forms fibrils over the $\mathrm{pH}$ range of 5.2 to 3.8, exhibiting a maximum at $\mathrm{pH} 4.4$, A25T TTR exhibits maximum amyloidogenicity at approximately $\mathrm{pH} 5$ and is amyloidogenic at $\mathrm{pH}$ as high as 6.4 (Fig. 1A). At the optimal $\mathrm{pH}$ for maximal fibril formation, A25T TTR forms 30\% more fibrils than WT, as judged by turbidity. Whereas WT TTR requires 72 hours to reach a maximum in amyloid fibril formation $(\mathrm{pH} 4.4$, $0.20 \mathrm{mg} / \mathrm{ml}$ TTR), the fibril formation of A25T TTR $(\mathrm{pH}$ $5.0,0.20 \mathrm{mg} / \mathrm{ml} \mathrm{TTR}$ ) is nearly complete within 1 hour (Fig. 1B). The fibril formation rate of A25T TTR is much faster than that of other pathogenic TTR tetramers (Hammarström et al, 2002) and is similar to that of monomeric TTR (Jiang et al, 2001b), suggesting that the activation barrier for tetramer dissociation is dramatically lowered. The rate and fibril yield of A25T TTR
$\mathbf{A}$

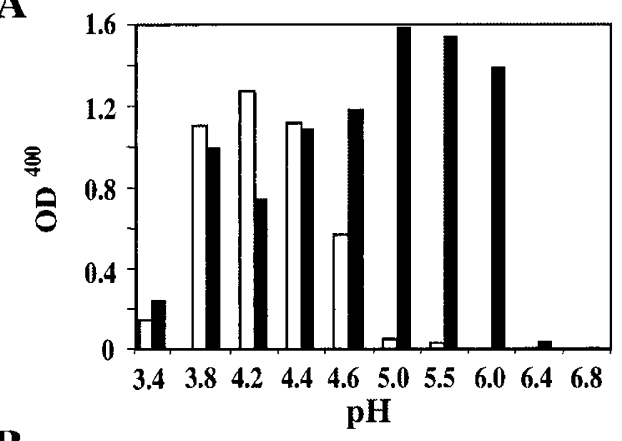

B

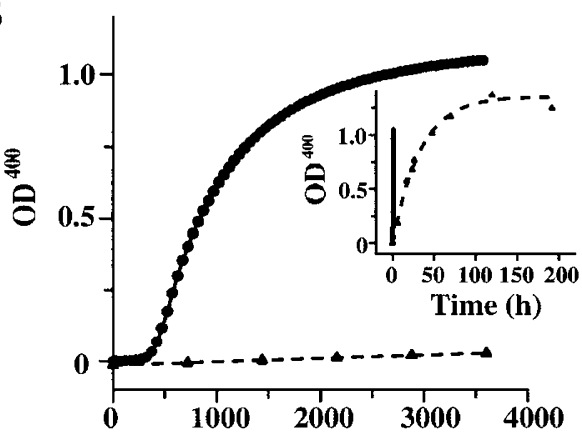

C

Time (s)

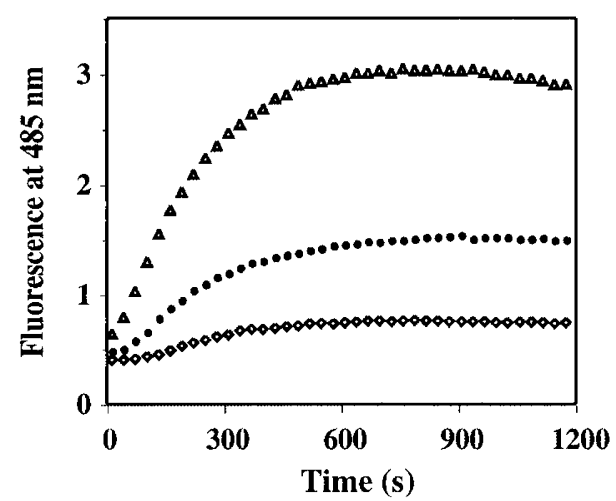

Figure 1.

Fibril formation as a function of $\mathrm{pH}$ and concentration. $\mathrm{A}, \mathrm{pH}$ dependence of A25T TTR (black) and wild-type (WT) TTR (white) amyloid fibril formation quantified by turbidity at $400 \mathrm{~nm}\left(0 \mathrm{D}^{400}\right)$ after incubation at $37^{\circ} \mathrm{C}$ for 72 hours. B, Time course of A25T TTR fibril formation (filled circles) at pH 5.0 $\left(37^{\circ} \mathrm{C}\right)$ and WT TTR fibril formation (filled triangles) at $\mathrm{pH} 4.4\left(37^{\circ} \mathrm{C}\right)$ monitored by turbidity at $400 \mathrm{~nm}\left(\mathrm{OD}^{400}\right)$. C, Concentration dependent time course of A25T TTR fibril formation at pH $5.0\left(37^{\circ} \mathrm{C}\right)$ monitered by thioflavin $\mathrm{T}$ fluorescence. Open triangles represent $0.2 \mathrm{mg} / \mathrm{ml} \mathrm{A25T}$, filled circles represent $0.1 \mathrm{mg} / \mathrm{ml}$ A25T, and open diamonds represent $0.05 \mathrm{mg} / \mathrm{ml} \mathrm{A25T}$.

is highly concentration dependent (Fig. 1C). The relative yield of A25T amyloid fibrils ( $\mathrm{pH} \mathrm{5,600} \mathrm{s)} \mathrm{de-}$ creases from $100 \%$ at a concentration of $0.2 \mathrm{mg} / \mathrm{ml}$ to $41.1 \%$ at $0.1 \mathrm{mg} / \mathrm{ml}$, and all of the way to $13.3 \%$ at an A25T concentration of $0.05 \mathrm{mg} / \mathrm{ml}$, demonstrating how the low serum concentrations of A25T can protect against amyloidogenesis.

Evaluating the Quaternary and Tertiary Structure Stability of A25T TTR Chaotropic denaturation studies are used in an attempt to quantify the thermodynamic influence of the A25T mutation on TTR quaternary and tertiary structural stability. Resveratrol binds the TTR tetramer, resulting in a large increase in its fluores- 
cence quantum yield, but resveratrol does not bind the monomer, allowing one to probe the tetramermonomer equilibrium by fluorescence. Resveratrol binding can overestimate the fraction tetramer as a result of Le Chatelier's principle; however, the fraction tetramer estimated by cross-linking and resveratrol binding is similar; hence, the overestimation may not be discernible. Unlike the WT tetramer $(0.1 \mathrm{mg} / \mathrm{ml}$, which begins to dissociate when the urea concentration exceeds $3 \mathrm{M}\left(\mathrm{C}_{\mathrm{m}}=3.3 \mathrm{M}\right.$ urea; Fig. 2A), the A25T TTR tetramer $(0.1 \mathrm{mg} / \mathrm{ml})$ commences dissociation at $1 \mathrm{M}$ urea, exhibiting complete dissociation in $2 \mathrm{M}$ urea, $\left(C_{m}=1.4 \mathrm{M}\right.$ urea; Fig. 2A). Recently, we reported that homotetramers composed of subunits that harbor pathogenic mutations are significantly less stable than WT on the basis of urea denaturation studies (Hammarström et al, 2002). The free energy of A25T tetramer dissociation extrapolated to physiologic conditions is $31.9 \mathrm{kcal} / \mathrm{mol}$, significantly less stable than any other TTR variant published to date. Another CNS variant D18G under investigation in the laboratory is so destabilized that it cannot tetramerize (P. Hammarström et al, unpublished data).

A25T tertiary structural stability can be ascertained by Trp fluorescence monitored urea denaturation
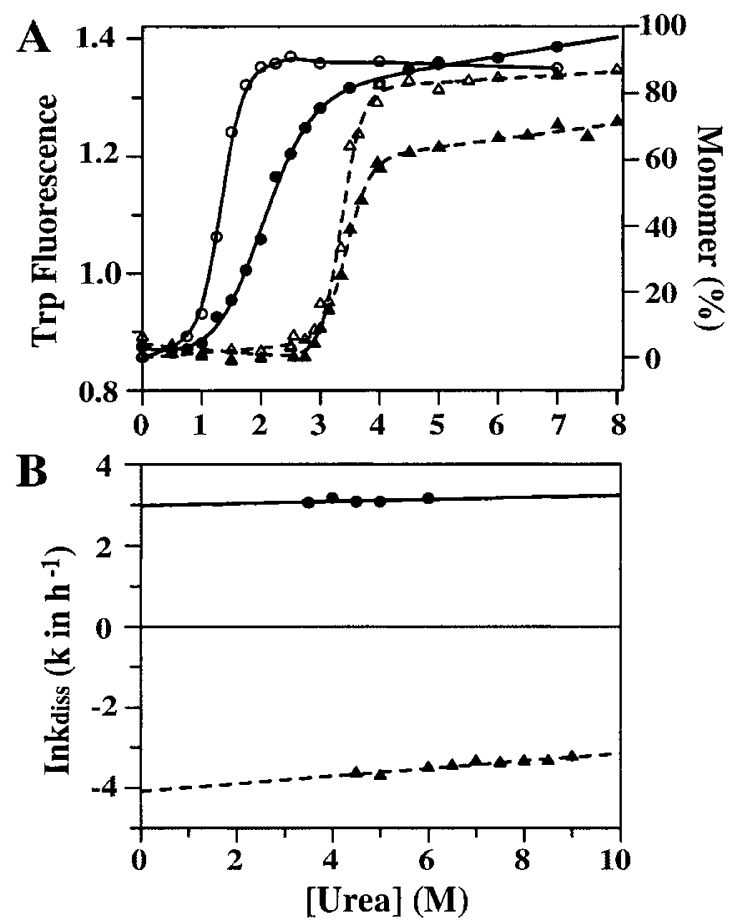

Figure 2.

Protein denaturation as a function of urea. A, Evaluation of the quarternary and tertiary structure stability of A25T (unbroken lines) and WT (broken lines) TTR as a function of urea concentration. Open symbols represent tetramer dissociation curves for A25T (circles) and WT (triangles) measured by resveratrol binding after 96 hours of incubation. Filled symbols represent tertiary structure unfolding for A25T (circles) and WT (triangles) measured by intrinsic tryptophan fluorescence. $B$, The logarithm of the rate of tetramer dissociation (Ink diss $; \mathrm{k}_{\text {diss }}$ in $\mathrm{h}^{-1}$ ) for A25T (filled circles) and WT TTR (filled triangles) as a function of urea concentration is plotted (employing urea concentrations that will not support tertiary structure refolding). The Ink ${ }_{\text {diss }}$ versus urea concentration plot is linear allowing extrapolation to physiological conditions. curves. The free energy of monomer unfolding of A25T is $2.80 \mathrm{kcal} / \mathrm{mol}\left(\mathrm{C}_{\mathrm{m}}=2 \mathrm{M}\right.$ urea$)$, which indicates that the A25T tertiary structure is less stable than that of WT TTR $\left(\mathrm{C}_{\mathrm{m}}=3.4 \mathrm{M}\right.$ urea; Fig. $\left.2 \mathrm{~A}\right)$. The tertiary structural instability exhibited by A25T is similar to the other CNS variant that we have recently characterized (D18G; $2.40 \mathrm{kcal} / \mathrm{mol}$ ) (P Hammarström et al, unpublished data). The $\mathrm{C}_{\mathrm{m}}$, $\mathrm{S}$ of $\mathrm{A} 25 \mathrm{~T}$ unfolding are independent of TTR concentration ( 0.01 to $0.1 \mathrm{mg} / \mathrm{ml})$, demonstrating that the tetramer $\leftrightarrow$ folded monomer and folded monomer $\leftrightarrow$ unfolded monomer equilibria are unlinked for this variant. In contrast, tetramer dissociation and monomer unfolding of WT TTR are clearly linked, as evidenced by the nearly coincident curves for resveratrol binding and tryptophan fluorescence (Fig. 2A). Furthermore, the $C_{m}$ for unfolding of WT TTR is dependent on TTR concentration, providing additional evidence that the quaternary and tertiary structural equilibria are linked, even at $0.01 \mathrm{mg} / \mathrm{ml}$ (A. Hurshman et al, unpublished data). Other variants studied thus far (V30M, L55P, and V122I) also exhibit linked equilibria (Hammarström et al, 2002); hence, the free energy of tetramer dissociation and monomer unfolding cannot be calculated by the methods described here for A25T. Nevertheless, although a direct comparison of the free energy is not possible, it is clear from the urea denaturation curves that the A25T mutation significantly destabilizes both the TTR quaternary and tertiary structure compared with WT and the other FAP variants.

\section{A25T Homotetramer Dissociation Kinetics}

The rate of tetramer dissociation can be ascertained by linking the slow dissociation step to rapid tertiary structural changes by a method described previously (Hammarström et al, 2002; Jiang et al, 2001a). Tertiary structural changes are easy to monitor by fluorescence in urea concentrations exceeding those required for subunit unfolding, rendering the process irreversible. The logarithm of the dissociation rate constant $\left(\operatorname{lnk}_{\text {diss }}\right)$ varies linearly with urea concentration (Fig. 2B), allowing extrapolations to physiologic conditions to be made. The $\mathrm{k}_{\text {diss }}$ of A25T TTR extrapolated to 0M urea was calculated to be 19.8 hours $^{-1}$, which equates to a half-life $\left(t_{1 / 2}\right)$ of only 2.1 minutes, 1200-fold faster than that of WT TTR and 126-fold faster than L55P tetramer dissociation (Hammarström et al, 2002), the mutation associated with the most aggressive systemic amyloidosis.

\section{Quantification of A25T and WT TTR in the Serum and CSF of a Patient with Heterozygous FAP}

The serum and CSF from a heterozygous patient with A25T TTR was analyzed by ELISA and immunoprecipitation followed by liquid chromatography/mass spectrometry (LC/MS). The total serum protein and albumin concentrations were normal $(76.0 \mathrm{mg} / \mathrm{ml}$ and $45.0 \mathrm{mg} / \mathrm{ml}$, respectively); however, the total TTR concentration was low $(0.0702 \mathrm{mg} / \mathrm{ml}$; normal, 0.2000 
to $0.4000 \mathrm{mg} / \mathrm{ml}$ ). The CSF was bloody and exhibited a high total protein level of $2.97 \mathrm{mg} / \mathrm{ml}$ and a high TTR concentration of $0.0242 \mathrm{mg} / \mathrm{ml}$ (normal, 0.0020 to $0.0200 \mathrm{mg} / \mathrm{ml}$ ), possibly as a result of asymptomatic subarachnoid hemorrhage. LC/MS was used to quantify the A25T:WT TTR ratio in serum and CSF. First, we examined the serum and CSF of a patient with heterozygous V30M FAP as a control. The LC/MS spectra of DTT-treated immunoprecipitated TTR from a patient with heterozygous V30M FAP showed equally intense major ion peaks of molecular mass $(\mathrm{m} / \mathrm{z})$ 13,762 \pm 1 and 13,794 \pm 1 (Fig. 3A), consistent with the $\left[\mathrm{M}+\mathrm{H}^{+}\right]$ion of the WT and V30M TTR monomer, respectively. The ratio of WT and V30M TTR ion count peak areas in serum was approximately 1:1, consistent with previous matrix-assisted laser desorption ionization/time-of-flight (MALDI/TOF) mass studies (Sekijima et al, 2001; Tachibana et al, 1999) and radioimmunoassay results (Nakazato et al, 1984). The LC/MS method applied to V30M heterozygotes CSF also showed a 1:1 ratio of V30M to WT ion counts (Fig. $3 A)$. Applying the same methods to determine the ratio of A25T TTR relative to WT in the heterozygote described within reveals that the serum level of A25T TTR was very low. In fact, no A25T TTR was detected in two of three examinations of serum TTR. In one attempt A25T TTR (molecular mass 13,792 m/z) was detected, but the peak area of A25T TTR was $<25 \%$ of that of WT TTR (Fig. 3B). In the CSF, the peak area of A25T TTR was $19 \%$ of that of WT TTR (Fig. 3B); however, this result did not reflect pure CSF because of a possible subarachnoid hemorrhage (contamination with blood).
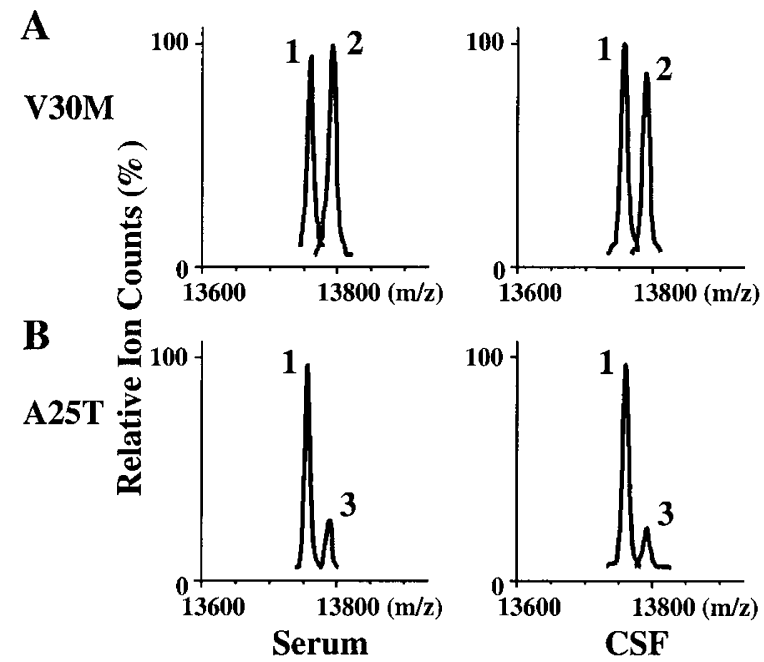

Figure 3.

Liquid chromatography/mass spectrometry (LC/MS) of immunoprecipitated TTR in heterozygotes. A, Analysis of WT and V30M TTR in the serum (left column) and CSF (right column) of a heterozygous V30M FAP patient (upper panels). Peak 1 represents the WT TTR monomer ion counts ( $\mathrm{m} / \mathrm{z} 13,762)$, and peak 2 indicates the V30M TTR monomer ion counts ( $\mathrm{m} / \mathrm{z} 13,794)$. B, WT and A25T TTR analysis for the Japanese FAP patient described within. Peak 1 represents the WT TTR monomer ion counts $(\mathrm{m} / \mathrm{z} 13,762)$, and peak 3 indicates the A25T TTR monomer ion counts ( $\mathrm{m} / \mathrm{z} 13,792)$. Note that the CSF is contaminated by blood (see text).
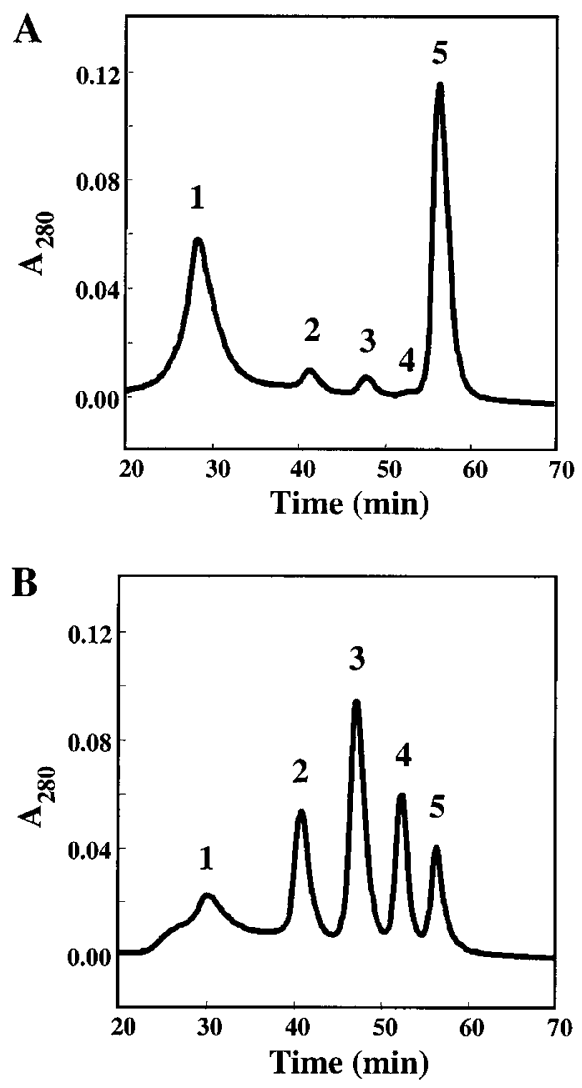

Figure 4.

Subunit exchange between $\mathrm{FT}_{2}-\mathrm{WT}$ and A25T homotetramers $\left(4^{\circ} \mathrm{C}\right)$. A, Chromatographic trace from analytical anion exchange after 0 hours of exchange. Peak 1 is composed of (A25T)4, peak 2 is composed of (A25T)3(FT 2 -WT)1, peak 3 is composed of $(A 25 T) 2\left(F_{2}-W T\right) 2$, peak 4 is composed of (A25T)1( $\left.\mathrm{FT}_{2}-\mathrm{WT}\right) 3$, and peak 5 is composed of $\left(\mathrm{FT}_{2}-\mathrm{WT}\right) 4$. B, Analytical anion exchange chromatographic trace after 24 hours of exchange. Organization is the same as that in $(A)$.

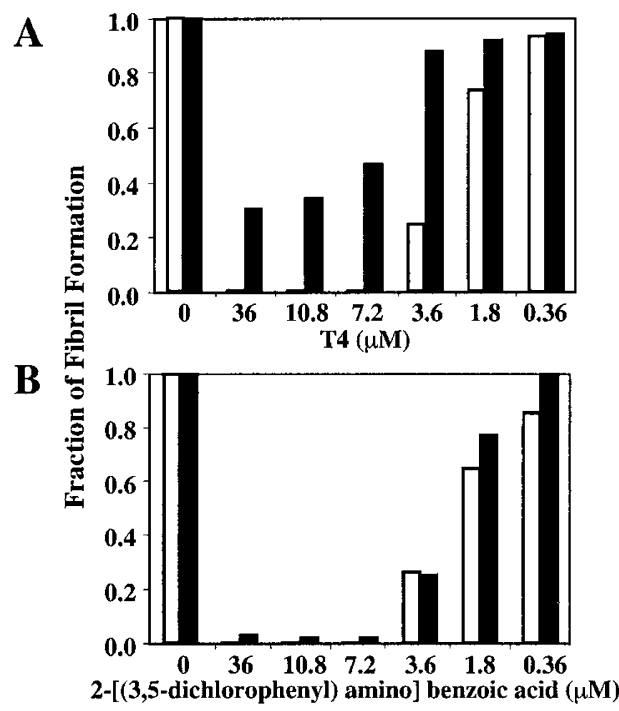

Figure 5.

Small molecule inhibition of A25T and WT TTR amyloid fibril formation. A, Inhibition of A25T (black bars; $3.6 \mu \mathrm{M}, \mathrm{pH}$ 5.0) and WT TTR (white bars; 3.6 $\mu \mathrm{M}, \quad \mathrm{pH}$ 4.4) amyloid fibril formation by $\mathrm{T}_{4}$ and (B) 2-[(3,5dichlorophenyl)amino] benzoic acid at pH 5 (A25T) or pH 4.4 (WT) as a function of inhibitor concentration as evaluated by turbidity at $400 \mathrm{~nm}\left(0 \mathrm{D}^{400}\right)$. 


\section{Can A25T and WT TTR Form Hybrid Tetramers}

Mixing equimolar amounts $(3.6 \mu \mathrm{M})$ of A25T and $\mathrm{FT}_{2}$-WT TTR homotetramers at $4^{\circ} \mathrm{C}$ reveals that a statistical distribution of tetramers composed of WT and A25T subunits can form by subunit exchange within 24 hours as discerned by ion exchange chromatography (Fig. 4). The other CNS TTR variant (D18G) under evaluation by this laboratory is unable to form significant amount of hybrid TTR tetramers with WT TTR by a subunit exchange mechanism (P. Hammarström et al, unpublished data).

\section{Inhibition of A25T TTR Fibril Formation by $T_{4}$ and 2-[(3,5-dichlorophenyl)amino]benzoic acid}

The efficacy of $\mathrm{T}_{4}$ as an inhibitor of TTR fibril formation was demonstrated by incubating varying concentrations of $T_{4}$ with TTR $(3.6 \mu \mathrm{M})$ under acidic conditions. WT TTR fibril formation was nearly completely inhibited by the addition of 2 eq of $\mathrm{T}_{4}(7.2 \mu \mathrm{M})$. In contrast, A25T TTR fibril formation was incompletely inhibited, even when 10 eq of $\mathrm{T}_{4}(36 \mu \mathrm{M})$ was used relative to A25T TTR concentration (Fig. 5A). 2-[(3,5dichlorophenyl)amino]benzoic acid is one of the best TTR amyloid fibril formation inhibitors discovered to date by our laboratory. This small molecule completely inhibited both WT and A25T TTR fibril formation at a concentration of $7.2 \mu \mathrm{M}$ (Fig. 5B).

\section{Discussion}

TTR amyloid fibril formation requires tetramer dissociation followed by a rapid conformational change in the monomer, allowing the TTR to misassemble into oligomers, protofilaments, and filaments as well as amorphous aggregates (Colon and Kelly, 1992; Kelly, 1996, 1997; Lai et al, 1996). The soluble intermediates preceding or formed in parallel with amyloid seem to be the entities responsible for pathology (Sousa et al, 2001). Biophysical data presented above on A25T reveals that this mutation destabilizes the quaternary structure of TTR (Fig. 2A). Moreover, the A25T homotetramer dissociates faster than any tetramer studied to date, which is significant because tetramer dissociation is known to be rate limiting for amyloid fibril formation (Figs. 1B and 2B). The ability of the A25T homotetramer to dissociate and misfold at $\mathrm{pHs}$ as high as 6.4 is a significant risk factor, as this $\mathrm{pH}$ can be achieved in several intra- and extracellular environments (Fig. 1A). The A25T TTR homotetramer dissociates 126-fold faster and is more destabilized than the L55P TTR homotetramer in the test tube, yet the age of disease onset for A25T is 42 years of age, whereas the age of onset for the severe systemic amyloidosis caused by the L55P mutation is in the second decade; (Jacobson et al, 1992; Yamamoto et al, 1994). We know that thermodynamic and kinetic stability considerations as well as the $\mathrm{pH}$ dependence of fibril formation correlate with disease severity (Hammarström et al, 2002; McCutchen et al, 1993, 1995). On the basis of these considerations, A25T TTR should result in an aggressive systemic amyloid dis- ease with early onset, but this is not case. Interestingly, the patient with the A25T mutation exhibited a low A25T serum TTR concentration ( $<25 \%$ of WT), suggesting that this factor protected the patient from an early-onset systemic disease. This is not surprising because self-assembly of the amyloidogenic intermediate is a concentration-dependent process (J.T. White et al, unpublished data). In fact, the rate of fibril formation and the total yield of fibrils diminished dramatically when the concentration of A25T TTR was reduced (Fig. 1C).

There are at least two possible explanations for the low serum A25T TTR concentration. One is decreased secretion of variant TTR from liver, and the other is rapid degradation of $\mathrm{A} 25 \mathrm{~T}$ TTR postsecretion. We propose that the low serum level of A25T TTR detected in this patient is a result of degradation by the quality control machinery of the cells that compose the liver. L55P TTR may represent the lowest stability tetramer amenable to efficient secretion, explaining why L55P carriers exhibit an early-onset systemic disease. This hypothesis will be tested by future studies. We speculate that the A25T variant leads to a CNS disease because of the high $\mathrm{T}_{4}$ concentration in the choroid plexus, which could chaperone enough A25T TTR out of the choroid plexus to facilitate amyloidosis (Dickson et al, 1987; Fan et al, 1999; Sawkar et al, 2002; Schreiber et al, 1990). $T_{4}$ binding is known to stabilize the quaternary structure (Miroy et al, 1996; Fig. 5A) and render D18G tetrameric by a tetramer stabilization mechanism at high concentrations. However, the $\mathrm{T}_{4}$ concentration in the CSF is not sufficient to stabilize A25T TTR (owing to the $\mathrm{K}_{\mathrm{d}}$ of $\mathrm{T}_{4}$ ) after secretion enabling TTR to dissociate and misfold into amyloid fibrils in the CSF. This hypothesis is consistent with the observation that A25T TTR deposits in the leptomeninges and subarachnoid spaceregions facing the CSF. It is also possible that $A 25 T$ prefers CNS deposition because of some unique feature of that environment, such as binding of the monomer to the leptomeningeal membrane. Other TTR variants seem to have a predilection toward tissue-selective deposition (Connors et al, 2000; Ikeda et al, 2002; Jacobson et al, 1996; Jenne et al, 1996; Ranlov et al, 1992).

Eight of $>80$ TTR disease-associated variants are reported to have CNS involvement at an early stage of pathology (Brett et al, 1999; Ellie et al, 2001; Garzuly et al, 1996; Ikeda et al, 2002; Mascalchi et al, 1999; Petersen et al, 1997; Uemichi et al, 1997, 1999) (Table 1). These TTR variants share common features, including a fifth decade age of disease onset, low serum variant TTR levels, and, in the two cases examined thus far, extreme mutation induced protein destabilization. TTR serum levels of several CNS-associated variants including D18G (P Hammarström et al, unpublished data), $\Delta$ V122 (Uemichi et al, 1997), Y114C (Ando et al, 1999), and A25T are very low relative to WT levels, unlike the situation in FAP heterozygotes that do not exhibit CNS involvement. The most destabilized TTR variant characterized to date (D18G) results in prominent CNS amyloidosis with benign low- 
Table 1. TTR Variants Associated with CNS Amyloidosis and Serum Levels

\begin{tabular}{|c|c|c|c|c|c|}
\hline $\begin{array}{l}\text { Mutations/Ethnic } \\
\text { background }\end{array}$ & Age of Onset & $\begin{array}{c}\text { CNS } \\
\text { Amyloidosis }\end{array}$ & $\begin{array}{l}\text { Systemic } \\
\text { Amyloidosis }\end{array}$ & $\begin{array}{l}\text { Serum Variant } \\
\text { TTR Level }\end{array}$ & $\begin{array}{l}\text { Protein } \\
\text { Stability }\end{array}$ \\
\hline D18G/Hungarian & $\begin{array}{c}36,37,53,51 \\
\text { (mean age: } 44.3 \text { ) }\end{array}$ & +++ & + & $\begin{array}{c}\text { very low } \\
\text { (undetectable) }\end{array}$ & $\begin{array}{l}\text { very low } \\
\text { (monomer) }\end{array}$ \\
\hline V30G/German & $\begin{array}{c}30,43,56,35,44, \\
47 \text { (mean age: } 42.5 \text { ) }\end{array}$ & +++ & + & n.d. & n.e. \\
\hline F64S/Italian & $28,<20,<20$ & +++ & ++ & n.d. & n.e. \\
\hline A36P/Italian & $\begin{array}{c}37,37,40 \text { (mean } \\
\text { age: } 38.0)\end{array}$ & +++ & ++ & n.d. & n.e. \\
\hline L12P/English & 38 & +++ & ++ & n.d. & n.e. \\
\hline G53E/French & $\begin{array}{c}\text { 37, } 42 \text { (mean age: } \\
39.5 \text { ) }\end{array}$ & +++ & +++ & n.d. & n.e. \\
\hline$\Delta$ V122/Ecuadorian & 57 & $++^{a}$ & +++ & Very low & n.e. \\
\hline Y114C/Japanese & $\begin{array}{c}39,34,31,34 \\
\text { (mean age: } 34.5)\end{array}$ & ++ & +++ & Very low & n.e. \\
\hline A25T/Japanese & 42 & ++ & ++ & $\begin{array}{c}\text { Very low } \\
(<25 \% \text { of } \\
\text { WT })\end{array}$ & $\begin{array}{l}\text { (unstable } \\
\text { tetramer) }\end{array}$ \\
\hline
\end{tabular}

CNS, central nervous system.

+++ , severe clinical symptoms resulting in death; ++ , moderate clinical symptoms; + , slight clinical symptoms or subclinical amyloid deposition; n.d., not described; n.e., not examined.

a The relationship between CNS symptoms and amyloidosis was not confirmed.

level systemic deposition, suggesting that extreme destabilization prevents systemic amyloidosis. The stability of A25T, which is between that of L55P and D18G, leads to a disease in which CNS symptoms and systemic amyloidosis symptoms appear at nearly the same time.

FAP was considered until recently to be an incurable disease; however, liver transplantation developed 10 years ago proves to be an effective therapeutic strategy for replacing the variant TTR gene in the liver by the WT gene-reversing systemic amyloidosis and halting progression of FAP pathology (Holmgren et al, 1993). Variant TTR in the serum disappears several days after liver transplantation; however, CSF levels of variant TTR do not significantly decrease even after long-term postsurgical observation (Adams et al, 2000; Ando et al, 1995). Hence, this approach will not correct CNS selective amyloidosis. More worrisome is that amyloid deposition on subarachnoid vessels and leptomeninges was found in a patient with V30M FAP (Ushiyama et al, 1991). Although CNS involvement in V30M FAP is not generally considered to be clinically significant, three reports question this generally held perception (Herrick et al, 1996; Horta et al, 1964; Sakashita et al, 2001). Therefore, CNS amyloidosis could be a future problem for the $>500$ patients who have received V30M transplantation (Familial Amyloidotic Polyneuropathy World Transplant Register, www.fapwtr.org/). The need to elucidate the precise mechanism of TTR-related CNS amyloidosis and to develop effective therapeutic strategies is compelling. Herein, we demonstrate that tetramer stabilizers such as 2-[(3,5-dichlorophenyl)amino]benzoic acid inhibit A25T amyloidosis in vitro (Fig. 5B) providing hope that compounds of this type that cross the blood-brain barrier could be useful in CNS-selective or -specific TTR amyloid diseases.

\section{Materials and Methods}

\section{Patient}

The patient is a 45-year-old Japanese man. At age 42, he first began to notice vertigo and nausea. Two years later, he developed a gait disturbance. Dysesthesia of the right hand and hearing loss appeared at age 45 . On examination, he had right sensorineural hearing loss, superficial and deep sensory disturbance of extremities, generalized areflexia, and ataxic gait. Motor nerve conduction velocities were decreased in both upper and lower extremities. Magnetic resonance imaging disclosed marked linear gadolinium enhancement over the surface of the brain and spinal cord. Sural nerve biopsy showed no abnormal findings such as amyloid deposition; however, biopsied leptomeninges disclosed heavy deposits of amyloid, which reacted with an anti-TTR antibody. We performed a genetic diagnosis for TTR-related amyloidosis with informed consent. Direct DNA sequencing of TTR exon 2 showed a single base transversion at the first nucleotide of codon 25 (GCC to ACC), indicating replacement of alanine by threonine in the protein (A25T). No other mutations were found in the coding region of the TTR gene.

\section{Protein Expression and Purification}

Recombinant A25T TTR was expressed in BL21/DE3 Epicurean gold Escherichia Coli (Stratagene, La Jolla, California) transformed with the $\mathrm{pmmH} \alpha$ plasmid, containing A25T TTR and ampicillin resistant genes. Expression and purification were performed as described previously (Lashuel et al, 1999). 


\section{Fibril Formation Assay}

A TTR stock solution $[0.4 \mathrm{mg} / \mathrm{ml}$ in $10 \mathrm{~mm}$ sodium phosphate, $100 \mathrm{~mm} \mathrm{KCl}, 1 \mathrm{~mm}$ EDTA, 1 mм DTT (pH 7)] was diluted 1:1 with $100 \mathrm{~mm}$ acidification buffer containing $100 \mathrm{~mm} \mathrm{KCl}, 1 \mathrm{~mm}$ EDTA, and $1 \mathrm{~mm}$ DTT. Citrate buffer was used when a final $\mathrm{pH}$ of $\leq 3.4$ was desired; acetate buffer was used when the $\mathrm{pH}$ range under evaluation was 3.8 to 5.8 , and phosphate buffer was used for evaluating amyloidogenesis from $\mathrm{pH} 6.2$ to 7.0. The influence of $T_{4}$ and 2-[(3,5-dichlorophenyl)amino]benzoic acid was evaluated by adding them to a $0.4 \mathrm{mg} / \mathrm{ml}$ TTR solution, which was incubated for 2 hours $\left(37^{\circ} \mathrm{C}\right)$ before the $\mathrm{pH}$ was dropped to 4.4 (WT TTR) or 5.0 (A25T TTR) via a 1:1 dilution with acetate buffer. All fibril formation samples were incubated at $37^{\circ} \mathrm{C}$ for 72 hours without stirring after acidification. The extent of fibril formation was probed by turbidity measurements at $400 \mathrm{~nm}$ on an HP $845 \times$ UV-visible spectrometer equipped with a Peltier temperature-controlled cell holder. Single-time point samples (72 hours) were vortexed immediately before the measurement to suspend the precipitate equally.

\section{Fibril Formation Kinetics}

Solutions of TTR $(0.4 \mathrm{mg} / \mathrm{ml})$ were mixed with an equal volume of $100 \mathrm{~mm}$ acetate buffer (with $100 \mathrm{~mm} \mathrm{KCl,} 1$ mM EDTA, and $1 \mathrm{~mm}$ DTT) to yield a final $\mathrm{pH}$ of 4.4 for WT TTR and 5.0 for A25T TTR. The samples were incubated at $37^{\circ} \mathrm{C}$ with stirring. The turbidity at 400 $\mathrm{nm}$ was continuously monitored over the course of 3600 seconds. Fibril formation kinetics of A25T TTR were also monitored by thioflavin $\mathrm{T}(\mathrm{ThT})$ fluorescence on an AVIV ATF-105 fluorometer (AVIV Instruments, Lakewood, NJ) with $440 \mathrm{~nm}$ excitation and 485 emission (J.T. White et al, unpublished data). For A25T TTR concentration-dependent studies of amyloidogenicity, $1 \mathrm{ml}$ of $100 \mathrm{~mm}$ sodium acetate buffer [with $100 \mathrm{~mm}$ $\mathrm{KCl}, 1 \mathrm{~mm}$ EDTA, and $1 \mathrm{~mm} \mathrm{DTT}(\mathrm{pH}$ 4.8)] was added to a $10 \times 10 \mathrm{~mm}$ cuvette equipped with circular stirbar along with $20 \mu \mathrm{l}$ of $2 \mathrm{~mm}$ ThT in $10 \mathrm{~mm}$ sodium phosphate, $100 \mathrm{~mm} \mathrm{KCl}(\mathrm{pH}$ 7.6). One milliliter of A25T TTR $(0.4 \mathrm{mg} / \mathrm{ml}$ or $0.2 \mathrm{mg} / \mathrm{ml}$ or $0.1 \mathrm{mg} / \mathrm{ml})$ in $10 \mathrm{~mm}$ sodium phosphate buffer [with $100 \mathrm{~mm} \mathrm{KCl}, 1 \mathrm{~mm}$ EDTA, and $1 \mathrm{~mm} \mathrm{DTT} \mathrm{(pH} \mathrm{7)]} \mathrm{was} \mathrm{added} \mathrm{to} \mathrm{the} \mathrm{cuvette}$ using a 1-ml titration syringe to start the time course. The final TTR concentration was half the initial concentration $(0.2 \mathrm{mg} / \mathrm{ml}$ or $0.1 \mathrm{mg} / \mathrm{ml}$ or $0.05 \mathrm{mg} / \mathrm{ml})$, and the final $\mathrm{pH}$ was 5.0. The samples were incubated at $37^{\circ} \mathrm{C}$ with stirring, and fluorescence intensity at 485 $\mathrm{nm}$ was continuously monitored over the course of 1800 seconds.

\section{Urea-Mediated TTR Tetramer Dissociation Measured by Resveratrol Binding}

Resveratrol displays a large increase in its fluorescence quantum yield and a blue shift upon binding to tetrameric TTR, but does not bind to the TTR monomer (X Jiang et al, unpublished data). Resveratrol binding standard curves were recorded to quantify the concentration of WT and A25T TTR tetramer ( 0 to 0.12 $\mathrm{mg} / \mathrm{ml} ; 0$ to $2.18 \mu \mathrm{M}_{\text {tetramer }}$ ) utilizing $18 \mu \mathrm{M}$ resveratrol. The fluorescence intensity at $394 \mathrm{~nm}\left({ }^{1394}\right)$ was plotted versus the concentration of TTR tetramer, exhibiting a linear fit as expected. Resveratrol fluorescence was recorded from 350 to $550 \mathrm{~nm}$ following excitation at $320 \mathrm{~nm}$. Samples containing TTR (0.01 to $0.1 \mathrm{mg} / \mathrm{ml}$; 0.18 to $\left.1.8 \mu \mathrm{M}_{\text {tetramer }}\right)$ were incubated $\left(25^{\circ} \mathrm{C}\right)$ in various concentrations of urea buffered with $50 \mathrm{~mm}$ phosphate (pH 7.0; $100 \mathrm{~mm} \mathrm{KCl}, 1 \mathrm{~mm}$ EDTA, $1 \mathrm{~mm}$ DTT) to evaluate tetramer stability. Urea solutions were checked by refractive index to verify the concentrations prepared by weight. After incubation ( 96 hours) $3.6 \mu \mathrm{l}$ of resveratrol from $2.5 \mathrm{~mm}$ stock solution (in DMSO) was added to a $500 \mu \mathrm{l}$ protein sample just prior to the measurement yielding a final concentration of $18 \mu \mathrm{M}$ resveratrol (Hammarström et al, 2001).

\section{Urea Mediated Monomer Unfolding Measured by Tryptophan Fluorescence}

Samples containing TTR $(0.01$ to $0.1 \mathrm{mg} / \mathrm{ml})$ were incubated $\left(25^{\circ} \mathrm{C}\right)$ in various concentrations of urea in $50 \mathrm{~mm}$ phosphate buffer $(\mathrm{pH} 7.0 ; 100 \mathrm{~mm} \mathrm{KCl}, 1 \mathrm{~mm}$ EDTA, $1 \mathrm{~mm}$ DTT) for 96 hours. Urea concentrations were verified as above. All TTR Trp fluorescence spectra were recorded over the range of 310 to 410 $\mathrm{nm}$ using an ATF 105 Aviv spectrofluorometer equipped with a thermostated cell holder using excitation at $295 \mathrm{~nm}$. Native wild-type TTR exhibits a fluorescence maximum at 337 to $338 \mathrm{~nm}$, whereas the unfolded protein shows maximum emission between 355 and $358 \mathrm{~nm}$. Each subunit of TTR has two tryptophans (residues 41 and 79 ). We used the 355 $\mathrm{nm}: 335 \mathrm{~nm}$ emission intensity ratio (F355/F335) to follow denaturation by the exposure of the tryptophans as a function of chaotrope concentrations. The ratio increased from 0.85 to 1.4 upon denaturation.

\section{Calculation of the Thermodynamic Stability of TTR}

The dissociation constant of the tetramer $\left(\mathrm{K}_{\text {diss }}\right)$, the free energy of tetramer dissociation $\left(\Delta G_{\text {diss }}\right)$, and the free energy of monomer unfolding $\left(\Delta G_{U}\right)$ were calculated using formulas: $\mathrm{K}_{\text {diss }}=256 \mathrm{c}^{3}(1-\alpha)^{4} \alpha^{-1}, \Delta \mathrm{G}_{\text {diss }}$ $=-R T \ln K_{\text {diss }}, \Delta G_{U}=-R T \ln \left(F_{U} / 1-F_{U}\right)$, where $c$ is the concentration of tetramer, $\alpha$ is the fraction tetramer and $F_{U}$ is the fraction of unfolding.

\section{Rate of Tetramer Dissociation Measured by Tryptophan Fluorescence}

The evaluation of tetramer dissociation rates was carried out using TTR $(0.1 \mathrm{mg} / \mathrm{ml} ; 50 \mathrm{~mm}$ phosphate buffer, $100 \mathrm{~mm} \mathrm{KCl,} \mathrm{pH} 7,25^{\circ} \mathrm{C}$ ) samples in 3.5 to 6.0 $\mathrm{M}$ urea (A25T TTR) or 4.5 to $9.0 \mathrm{M}$ urea (WT TTR), concentrations in the post-transition region for tertiary structural changes. The Trp fluorescence emission ratio $(\mathrm{F} 355 / \mathrm{F} 335)$ as a function of time $\left(25^{\circ} \mathrm{C}\right)$ was measured to evaluate the tetramer dissociation rate by linking it to tertiary structural changes, as described in detail previously (Hammarström et al, 2002; Jiang et al, 2001a). The kinetic data fit well to a single expo- 
nential function: $1^{355 / 335}=1^{355 / 335} N+A\left(1-e^{-k d i s s ~ t}\right)$; where $\left.\right|^{355 / 335}$ is the native protein fluorescence intensity ratio $(355 / 335 \mathrm{~nm}), A$ is the amplitude difference, $\mathrm{k}_{\text {diss }}$ is the tetramer dissociation rate constant, and $t$ is time in hours.

\section{Evaluating the Ability of A25T TTR to Exchange Subunits with WT TTR}

Equal concentrations $(3.6 \mu \mathrm{M})$ of two different TTR tetramers, $\mathrm{FT}_{2}-\mathrm{WT}$ and $\mathrm{A} 25 \mathrm{~T}$, were mixed and incubated at $4^{\circ} \mathrm{C}$ for 24 hours. The extent of hybrid tetramer formation was evaluated by analytical ion exchange chromatography as described previously (Hammarström et al, 2001; Schneider et al, 2001).

\section{ELISA Quantification of TTR Concentration in Human Serum and CSF}

ELISA quantification of TTR concentration was performed as described previously (Purkey et al, 2001). Briefly, $100-\mu$ l samples of recombinant TTR of known concentration and serum samples (diluted $4000 \times$ ) or CSF samples (diluted $200 \times$ ) were applied to an Immulon-4HBX microtiter plate (Thermal Labsystems, Helsinki, Finland) coated with antihuman prealbumin (TTR) antibody (DiaSorin, Stillwater, Minnesota) and incubated at $4^{\circ} \mathrm{C}$ for 24 hours. The Ab-bound TTR was then allowed to react with alkaline phosphataseconjugated goat antihuman prealbumin (TTR) antibody (EY Laboratories). Bound alkaline phosphatase activities were assayed by color development using the ELISA substrate solution from the GIBCO/BRL ELISA amplification system (Life Technologies).

\section{Immunoprecipitation and LC/MS Analysis of Serum and CSF TTR}

A 1.5-ml Eppendorf tube was filled with $100 \mu$ l of serum or $500 \mu \mathrm{l}$ of CSF from the patient. A 1:1 gel/TSA (10 mm Tris $\mathrm{HCl}, \mathrm{pH} 8.0 / 140 \mathrm{~mm} \mathrm{NaCl} / 0.025 \% \mathrm{NaN}_{3}$ ) slurry (10 $\mu$ ) of quenched Sepharose (Purkey et al, 2001) was added to the solution and incubated on a rocker at 18 rpm and $4^{\circ} \mathrm{C}$ for 1 hour. After centrifugation $(16,000 \times g)$, $100 \mu \mathrm{l}$ of a 1:1 gel/TSA slurry of the anti-TTR antibodyconjugated Sepharose was added to the supernatant, and the tube was rocked at $4^{\circ} \mathrm{C}$ for 20 minutes. The samples were centrifuged $(16,000 \times g)$, and the supernatant was removed. The gel was washed with $1 \mathrm{ml}$ of TSA $0.05 \%$ saponin (Fisher Scientific) $(3 \times, 10$ minutes each) at $4^{\circ} \mathrm{C}$ and additionally with $1 \mathrm{ml}$ of TSA $(2 \times, 10$ minutes each) at $4^{\circ} \mathrm{C}$. The samples were centrifuged $(16,000 \times g)$, the final wash was removed, and $155 \mu \mathrm{l}$ of $100 \mathrm{~mm}$ triethylamine $(\mathrm{pH} 11.5)$ was added to elute the TTR from the antibodies. After gentle agitation at $4^{\circ} \mathrm{C}$ for 30 minutes, the sample was centrifuged $(16,000 \times g)$ and $145 \mu \mathrm{l}$ of the supernatant containing TTR was removed. The supernatant was treated with $14.5 \mu \mathrm{l}$ of $1 \mathrm{M}$ DTT at $100^{\circ} \mathrm{C}$ for 15 minutes. Forty microliters of each sample was injected on to a Hewlett-Packard 1100-MSD massspectrometer, running a linear gradient of acetonitrile $(0 \%$ to $100 \%)$ in water. Both the water and the acetonitrile phases are acidified with TFA (0.05\%).

\section{Acknowledgments}

We thank E. Powers and A. Hurshman for help with evaluating thermodynamic parameters, J.T. White for help in the fibril formation assay, R.L. Wiseman for help in the subunit exchange assay, and D. French for help with ELISA quantification.

\section{References}

Adams D, Samuel D, Goulon-Goeau C, Nakazato M, Costa PM, Feray C, Plante V, Ducot B, Ichai P, Lacroix C, Metral S, Bismuth H, and Said G (2000). The course and prognostic factors of familial amyloid polyneuropathy after liver transplantation. Brain 123:1495-1504.

Ando Y, Almeida M, Ohlsson PI, Ando E, Negi A, Suhr O, Terazaki H, Obayashi K, Ando M, and Saraiva MJ (1999). Unusual self-association properties of transthyretin Y114C related to familial amyloidotic polyneuropathy: Effects on detection and quantification. Biochem Biophys Res Commun 261:264-269.

Ando $\mathrm{Y}$, Tanaka $\mathrm{Y}$, Nakazato M, Ericzon BG, Yamashita T, Tashima K, Sakashita N, Suga M, Uchino M, and Ando M (1995). Change in variant transthyretin levels in patients with familial amyloidotic polyneuropathy type I following liver transplantation. Biochem Biophys Res Commun 211:354-358.

Brett M, Persey MR, Reilly MM, Revesz T, Booth DR, Booth SE, Hawkins PN, Pepys MB, and Morgan-Hughes JA (1999). Transthyretin Leu12Pro is associated with systemic, neuropathic and leptomeningeal amyloidosis. Brain 122:183-190.

Colon W and Kelly JW (1992). Partial denaturation of transthyretin is sufficient for amyloid fibril formation in vitro. Biochemistry 31:8654-8660.

Connors LH, Richardson AM, Theberge R, and Costello CE (2000). Tabulation of transthyretin (TTR) variants as of 1/1/ 2000. Amyloid 7:54-69.

Dickson PW, Aldred AR, Menting JG, Marley PD, Sawyer WH, and Schreiber G (1987). Thyroxine transport in choroid plexus. J Biol Chem 262:13907-13915.

Ellie E, Camou F, Vital A, Rummens C, Grateau G, Delpech $M$, and Valleix S (2001). Recurrent subarachnoid hemorrhage associated with a new transthyretin variant (Gly53Glu). Neurology 57:135-137.

Fan JQ, Ishii S, Asano N, and Suzuki Y (1999). Accelerated transport and maturation of lysosomal alpha-galactosidase $\mathrm{A}$ in Fabry lymphoblasts by an enzyme inhibitor. Nat Med 5:112-115.

Garzuly F, Wisniewski T, Brittig F, and Budka H (1996). Familial meningocerebrovascular amyloidosis, Hungarian type, with mutant transthyretin (TTR Asp18Gly). Neurology 47:1562-1567.

Hammarström $P$, Jiang $X$, Hurshman AR, Powers ET, and Kelly JW (2002). Sequence-dependent denaturation energetics: A major determinant in amyloid disease diversity. Proc Natl Acad Sci USA 99:16927-16932.

Hammarström P, Schneider F, and Kelly JW (2001). Transsuppression of misfolding in an amyloid disease. Science 293:2459-2462.

Herrick MK, DeBruyne K, Horoupian DS, Skare J, Vanefsky MA, and Ong T (1996). Massive leptomeningeal amyloidosis associated with a Val30Met transthyretin gene. Neurology 47:988-992. 
Holmgren G, Ericzon BG, Groth CG, Steen L, Suhr O, Andersen O, Wallin BG, Seymour A, Richardson S, Hawkins PN, and Pepys MB (1993). Clinical improvement and amyloid regression after liver transplantation in hereditary transthyretin amyloidosis. Lancet 341:1113-1116.

Horta JDS, Filipe I, and Duarte S (1964). Portuguese polyneuritic familial type amyloidosis. Pathol Microbiol 27:809-825.

Ikeda S, Nakazato M, Ando Y, and Sobue G (2002). Familial transthyretin-type amyloid polyneuropathy in Japan: Clinical and genetic heterogeneity. Neurology 58:1001-1007.

Jacobson DR, McFarlin DE, Kane I, and Buxbaum JN (1992). Transthyretin Pro55, a variant associated with early-onset, aggressive, diffuse amyloidosis with cardiac and neurologic involvement. Hum Genet 89:353-356.

Jacobson DR, Pastore R, Pool S, Malendowicz S, Kane I, Shivji A, Embury SH, Ballas SK, and Buxbaum JN (1996). Revised transthyretin lle 122 allele frequency in AfricanAmericans. Hum Genet 98:236-238.

Jenne DE, Denzel K, Blatzinger P, Winter P, Obermaier B, Linke RP, and Altland K (1996). A new isoleucine substitution of $\mathrm{Val}-20$ in transthyretin tetramers selectively impairs dimerdimer contacts and causes systemic amyloidosis. Proc Natl Acad Sci USA 93:6302-6307.

Jiang X, Buxbaum JN, and Kelly JW (2001a). The V122I cardiomyopathy variant of transthyretin increases the velocity of rate-limiting tetramer dissociation, resulting in accelerated amyloidosis. Proc Natl Acad Sci USA 98:14943-14948.

Jiang X, Smith CS, Petrassi HM, Hammarström P, White JT, Sacchettini JC, and Kelly JW (2001b). An engineered transthyretin monomer that is nonamyloidogenic, unless it is partially denatured. Biochemistry 40:11442-11452.

Kelly JW (1996). The alternative conformations of amyloidogenic proteins and their multi-step assembly pathways. Curr Opin Struct Biol 6:11-17.

Kelly JW (1997). Amyloid fibril formation and protein misassembly: A structural quest for insights into amyloid and prion diseases. Structure 5:595-600.

Lai Z, Colon W, and Kelly JW (1996). The acid-mediated denaturation pathway of transthyretin yields a conformational intermediate that can self-assemble into amyloid. Biochemistry 35:6470-6482.

Lashuel HA, Wurth C, Woo L, and Kelly JW (1999). The most pathogenic transthyretin variant, L55P, forms amyloid fibrils under acidic conditions and protofilaments under physiological conditions Biochemistry 38:13560-13573.

Mascalchi M, Salvi F, Pirini MG, D’Errico A, Ferlini A, Lolli F, Plasmati R, Tessa C, Villari N, and Tassinari CA (1999). Transthyretin amyloidosis and superficial siderosis of the CNS. Neurology 53:1498-1503.

McCutchen SL, Colon W, and Kelly JW (1993). Transthyretin mutation Leu-55-Pro significantly alters tetramer stability and increases amyloidogenicity. Biochemistry 32:12119-12127.

McCutchen SL, Lai Z, Miroy GJ, Kelly JW, and Colon W (1995). Comparison of lethal and nonlethal transthyretin variants and their relationship to amyloid disease. Biochemistry 34:13527-13536.

Miroy GJ, Lai Z, Lashuel HA, Peterson SA, Strang C, and Kelly JW (1996). Inhibiting transthyretin amyloid fibril formation via protein stabilization. Proc Natl Acad Sci USA 93:15051-15056.
Nakazato M, Kangawa K, Minamino N, Tawara S, Matsuo H, and Araki S (1984). Radioimmunoassay for detecting abnormal prealbumin in the serum for diagnosis of familial amyloidotic polyneuropathy (Japanese type). Biochem Biophys Res Commun 122:719-725.

Petersen RB, Goren H, Cohen M, Richardson SL, Tresser N, Lynn A, Gali M, Estes M, and Gambetti P (1997). Transthyretin amyloidosis: A new mutation associated with dementia. Ann Neurol 41:307-313.

Purkey HE, Dorrell MI, and Kelly JW (2001). Evaluating the binding selectivity of transthyretin amyloid fibril inhibitors in blood plasma. Proc Natl Acad Sci USA 98:5566-5571.

Ranlov I, Alves IL, Ranlov PJ, Husby G, Costa PP, and Saraiva MJ (1992). A Danish kindred with familial amyloid cardiomyopathy revisited: Identification of a mutant transthyretin-methionine111 variant in serum from patients and carriers. Am J Med 93:3-8.

Sakashita N, Ando Y, Jinnouchi K, Yoshimatsu M, Terazaki $\mathrm{H}$, Obayashi K, and Takeya M (2001). Familial amyloidotic polyneuropathy (ATTR Val30Met) with widespread cerebral amyloid angiopathy and lethal cerebral hemorrhage. Pathol Int 51:476-480.

Sawkar AR, Cheng WC, Beutler E, Wong CH, Balch WE, and Kelly JW (2002). Chemical chaperones increase the cellular activity of N370S $\beta$-glucosidase: A therapeutic strategy for Gaucher disease. Proc Natl Acad Sci USA 99:15428-15433.

Schneider F, Hammarström P, and Kelly JW (2001). Transthyretin slowly exchanges subunits under physiological conditions: A convenient chromatographic method to study subunit exchange in oligomeric proteins. Protein Sci 10:1606-1613.

Schreiber G, Aldred AR, Jaworowski A, Nilsson C, Achen MG, and Segal MB (1990). Thyroxine transport from blood to brain via transthyretin synthesis in choroid plexus. Am J Physiol 258:R338-R345.

Sekijima Y, Tokuda T, Kametani F, Tanaka K, Maruyama K, and Ikeda $S$ (2001). Serum transthyretin monomer in patients with familial amyloid polyneuropathy. Amyloid 8:257-262.

Sousa MM, Cardoso I, Fernandes R, Guimaraes A, and Saraiva MJ (2001). Deposition of transthyretin in early stages of familial amyloidotic polyneuropathy: Evidence for toxicity of nonfibrillar aggregates. Am J Pathol 159:1993-2000.

Tachibana N, Tokuda T, Yoshida K, Taketomi T, Nakazato M, Li YF, Masuda Y, and Ikeda S (1999). Usefulness of MALDI/ TOF mass spectrometry of immunoprecipitated serum variant transthyretin in the diagnosis of familial amyloid polyneuropathy. Amyloid 6:282-288.

Uemichi T, Liepnieks JJ, and Benson MD (1997). A trinucleotide deletion in the transthyretin gene (delta $V 122$ ) in a kindred with familial amyloidotic polyneuropathy. Neurology 48:1667-1670.

Uemichi T, Uitti RJ, Koeppen AH, Donat JR, and Benson MD (1999). Oculoleptomeningeal amyloidosis associated with a new transthyretin variant Ser64. Arch Neurol 56:1152-1155.

Ushiyama M, Ikeda S, and Yanagisawa N (1991). Transthyretintype cerebral amyloid angiopathy in type I familial amyloid polyneuropathy. Acta Neuropathol (Berl) 81:524-528.

Yamamoto K, Hsu SP, Yoshida K, Ikeda S, Nakazato M, Shiomi K, Cheng SY, Furihata K, Ueno I, and Yanagisawa N (1994). Familial amyloid polyneuropathy in Taiwan: Identification of transthyretin variant (Leu55Pro). Muscle Nerve 17:637-641. 